\title{
Alkaline phosphatase activity of marine bacteria studied with ELF 97 substrate: success and limits in the P-limited Mediterranean Sea
}

\author{
France Van Wambeke ${ }^{1, *}$, Jiří Nedoma $^{2}$, Solange Duhamel ${ }^{1}$, Philippe Lebaron ${ }^{3,4}$ \\ ${ }^{1}$ Laboratoire de Microbiologie, Géochimie et Ecologie Marines, CNRS, UMR 6117, Case 901, \\ Centre d'Océanologie de Marseille, Université de la Méditerranée - Campus de Luminy, 13288 Marseille Cedex 9, France \\ ${ }^{2}$ Biological Centre of the Academy of Sciences of the Czech Republic, Hydrobiological Institute, Na sádkách 7 , \\ 37005 České Budějovice, Czech Republic \\ ${ }^{3}$ Université Pierre et Marie Curie-Paris 6, and ${ }^{4}$ CNRS, UMR7621, 66650 Banyuls-sur-Mer, France
}

\begin{abstract}
The fluorogenic substrate Enzyme-Labeled Fluorescence 97 (ELF-P) is hydrolyzed by the P-cleaving enzyme phosphatase, producing ELF 97 alcohol (ELFA), a fluorescent-insoluble product. This reaction is used for monitoring phosphatase activity at the single-cell level. Most frequently, ELF-P has been used to determine the P-limitation status of microphytoplankton, but rarely of heterotrophic bacteria. We incubated ELF-P on filters to monitor marine bacterial cultures and oligotrophic Mediterranean Sea samples. Results were compared to classical measurements of bulk alkaline phosphatase activity using the fluorogenic substrate 4-methylumbelliferyl phosphate (MUF-P). A high percentage of the cultured cells were labeled with ELFA (the ratio of ELFA spots to total DAPI counts in P-limited cultures ranged from 26 to $100 \%$, depending on the strain). In contrast, this ratio never exceeded $0.01 \%$ in Mediterranean samples, even when P was demonstrated to be a significant limiting factor. This protocol is useful for application on cruises and with cultures, but was not sufficiently sensitive to detect P-stressed bacterial cells in oligotrophic marine environments.
\end{abstract}

KEY WORDS: Marine bacteria - Alkaline phosphatase - Cell specific activity - Ectoenzyme • ELF97 phosphatase substrate $\cdot$ Phosphorus limitation

\section{INTRODUCTION}

Developing new techniques for detecting phosphorus (P)-stress in bacteria at the cell level from natural environments is a challenge in microbial ecology. Such developments are important in understanding how P-limitation can affect both the structure and the functional role of bacterial communities. The molecule 2-(5'-chloro2'-phosphoryloxyphenyl)-6-chloro-4-(3H)-quinazolinone (Enzyme-Labeled-Fluorescence 97 phosphatase substrate [ELF-P], Molecular Probes) is a soluble substrate, which, when cleaved by the cell's enzyme (phosphatase), produces ELF 97 alcohol (ELFA), a bright fluorescent yellow-green precipitate labeling the site of en- zymatic activity (Gonzalez-Gil et al. 1998). In aquatic systems, this technique has mainly been used as a tool for identifying P-limited phytoplankton cells. To date, only 4 published studies have focused on natural bacterial communities. This includes studies on activated sludge (Van Ommen Kloeke \& Geesey 1999), an acidified lake (Nedoma \& Vrba 2006), and bacterial colonies and biofilms (Huang et al. 1998, Espeland \& Wetzel 2001). In most of these studies, however, the abundance and activity of bacteria were fairly high.

The aims of the present study were (1) to test an easy protocol (suitable for research expeditions) on marine isolates, and (2) to test this technique in the Mediterranean Sea under P-limited conditions. 


\section{MATERIALS AND METHODS}

Two marine species were used: Alteromonas infernus and Pseudomonas denitrificans. Cells were grown in minimum requirement medium (Lyman \& Fleming 1940) with a single source of carbon (C) and energy and a single source of $\mathrm{P}$, plus trace amounts of iron and vitamins. The concentration of organic $\mathrm{C}$ (as glucose or pyruvate) was low (Table 1) in order to obtain less dense cultures. Different concentrations of inorganic $P$ were added to produce diverse initial $\mathrm{C} / \mathrm{P}$ ratios of the provided substrates (Table 1, Expts a and c). A. infernus was also grown in natural seawater amended with pyruvate (Table 1, Expt b). Seawater was aged in the dark for 1 mo at $4^{\circ} \mathrm{C}$ to remove most nutrients. This seawater was $0.2 \mu \mathrm{m}$ filtered, and the filtrate was supplemented with excess nitrogen $\left(0.1 \mathrm{mM} \mathrm{NH}_{4} \mathrm{Cl}\right)$, carbon (0.33 mM C-pyruvate), and trace amounts of iron and vitamins. Phosphate $(16.5 \mu \mathrm{M})$ was added only in the $+\mathrm{P}$ treatment.

The station DYFAMED (Marty et al. 2002) was studied for ELF application at the end of March 2003. Soluble reactive $\mathrm{P}$ (SRP) and dissolved organic P (DOP), determined as the difference between filtered samples before and after wet-oxidation, were measured according to standard colorimetric techniques (Raimbault et al. 1999).

Alkaline phosphatase (AP) activity was measured fluorometrically using 4-methylumbelliferyl phosphate (MUF-P). The linear increase in fluorescence in seawater with added MUF-P was followed over time (excitation at $365 \mathrm{~nm}$ and emission at $460 \mathrm{~nm}$ ) with a Kontron SFM 23B spectrofluorometer. For in situ and culture samples, we used MUF-P concentrations of
1 and $50 \mu \mathrm{M}$, respectively, which were found to be saturating in preliminary experiments. MUF-P tracks both dissolved AP activity and particle-associated (mostly microorganisms) AP activity. Dissolved-associated AP activity was negligible in cultures $(<3 \%)$ and could reach up to $36 \%$ of measured phosphatase activity at the DYFAMED station (results not shown).

Contrary to MUF-P, ELF-P substrate provides information on particle-associated AP. The Endogenous Phosphatase Detection Kit (Molecular Probes E 6601) was used. Component $A\left(A_{\text {kit }}\right)$ was diluted 1/20 in component $\mathrm{B}\left(\mathrm{B}_{\mathrm{kit}}\right)$ of the kit in accordance with the manufacturer's instruction to generate the solution applied to the slides. Immediately after filtration of a water sample (live sample) onto a $0.2 \mu \mathrm{m}$ pore size black polycarbonate filter, the filter was transferred onto a glass slide, and $40 \mu \mathrm{l}$ of the diluted solution $\mathrm{A}_{\text {kit }} / \mathrm{B}_{\text {kit }}$ were applied to the surface of the filter and gently spread with a plastic tip. The slide was then put into a horizontal, capped $50 \mathrm{ml}$ plastic tube to which wet paper was added to prevent evaporation. Following a $1 \mathrm{~h}$ incubation at room temperature in the dark, the filter was removed, put briefly on a piece of absorbing paper, and then transferred into a $47 \mathrm{~mm}$ Petri dish containing a $47 \mathrm{~mm}$ absorbent pad (AP100 Millipore) soaked with a solution of phosphate buffered saline (PBS, $10 \mathrm{mM}, \mathrm{pH} 7.5$ ) and $1 \%$ formaldehyde to stop the activity. The filter was transferred successively onto 3 PBS-formalin soaked pads, and left $5 \mathrm{~min}$ on each one. The filter was then airdried on a piece of absorbent paper before being transferred onto a glass slide. Forty $\mu \mathrm{l}$ of a DAPI solution $\left(25 \mu \mathrm{g} \mathrm{ml}^{-1}\right)$ were added, and the filter was incubated for 10 min in the dark. The filter was dried again on absorbent paper and mounted on a glass slide. The yellow

Table 1. Pseudomonas denitrificans, Alteromonas infernus. Summary of alkaline phosphatase (AP) activity in bacterial cultures, including initial conditions and the main results (bacterial numbers, ELFA spots, MUF-P based activities, and specific activities). BN: bacterial numbers (DAPI counts)

\begin{tabular}{|c|c|c|c|c|c|}
\hline $\begin{array}{l}\text { Code of experiment: } \\
\text { Medium: } \\
\text { Carbon enrichment: }\end{array}$ & $\begin{array}{r}\text { Pseudomona } \\
\text { Artificial } \\
\text { Glu }\end{array}$ & $\begin{array}{l}\text { denitrificans } \\
\text { a } \\
\text { seawater } \\
\text { ose }\end{array}$ & $\begin{array}{r}\text { Alteromona } \\
\text { Natural } \\
\text { Pyru }\end{array}$ & $\begin{array}{l}\text { s infernus } \\
\text { eawater } \\
\text { vate }\end{array}$ & $\begin{array}{c}\text { Alteromonas infernus } \\
\text { c } \\
\text { Artificial seawater } \\
\text { Pyruvate }\end{array}$ \\
\hline Concentration of $\mathrm{C}$ (mM C) & \multicolumn{2}{|c|}{3.3} & \multicolumn{2}{|c|}{0.33} & 0.55 \\
\hline $\mathrm{NH}_{4} \mathrm{Cl}$ addition (mM N) & \multicolumn{2}{|c|}{6.7} & \multicolumn{2}{|c|}{0.1} & 6.7 \\
\hline $\mathrm{KH}_{2} \mathrm{PO}_{4}$ addition $(\mu \mathrm{MP})$ & 165 & 8.25 & 16.5 & 0 (in situ 0.61 ) & 5.8 \\
\hline Conditions & Excess $\mathrm{P}$ & Low $\mathrm{P}$ & Excess P & Low $\mathrm{P}$ & Equilibrium \\
\hline Duration of the culture (d) & 13 & 13 & 13 & 13 & 8 \\
\hline $\begin{array}{l}\text { Period of max. BN (d) } \\
\text { Max. BN }\left(\mathrm{ml}^{-1}\right)\end{array}$ & $\begin{array}{c}8-13 \\
1.2-1.5 \times 10^{8}\end{array}$ & $\begin{array}{c}7-11 \\
3.1-4.6 \times 10^{6}\end{array}$ & $\begin{array}{c}5-8 \\
2.0-2.6 \times 10^{7}\end{array}$ & $\begin{array}{c}7-9 \\
1.2-1.7 \times 10^{7}\end{array}$ & $\begin{array}{c}3-7 \\
3.2-4.5 \times 10^{7}\end{array}$ \\
\hline $\begin{array}{l}\text { Period of max. AP activities (MUF-based) (d) } \\
\text { Max. MUF-based AP activities }\left(\mathrm{nM} \mathrm{h}^{-1}\right)\end{array}$ & $\begin{array}{r}11-13 \\
22-38\end{array}$ & $\begin{array}{c}6-8 \\
43-154\end{array}$ & $\begin{array}{c}8-13 \\
1400-2000\end{array}$ & $\begin{array}{c}6-9 \\
6000-9600\end{array}$ & $\begin{array}{c}8 \\
37000\end{array}$ \\
\hline $\begin{array}{l}\text { Period of max. specific activities (d) } \\
\text { Specific activities }\left(\text { amol cell }{ }^{-1} \mathrm{~h}^{-1} \text { ) }\right.\end{array}$ & $\begin{array}{c}0-13 \\
0.1-6.5\end{array}$ & $\begin{array}{c}6-8 \\
16-33\end{array}$ & $\begin{array}{c}2-13 \\
10-160\end{array}$ & $\begin{array}{c}2-13 \\
440-1000\end{array}$ & $\begin{array}{c}8 \\
1300\end{array}$ \\
\hline $\begin{array}{l}\text { Period of max. ELFA spots }(\mathrm{d}) \\
\text { Max. ELFA spots }\left(\mathrm{ml}^{-1}\right)\end{array}$ & $\begin{array}{c}8-12 \\
3-5 \times 10^{4}\end{array}$ & $\begin{array}{c}7-11 \\
3.4-7.0 \times 10^{5}\end{array}$ & $\begin{array}{c}2-13 \\
5.1 \pm 1.8 \times 10^{6}\end{array}$ & $\begin{array}{c}2-13 \\
4.8 \pm 3.0 \times 10^{6}\end{array}$ & $\begin{array}{c}1.2-5 \\
2-7 \times 10^{7}\end{array}$ \\
\hline Ratio ELFA spots / BN (\%) & $0.02-0.05$ & $9-17$ & $30 \pm 11$ & $46 \pm 28$ & $172 \pm 114$ \\
\hline
\end{tabular}


fluorescence of ELFA spots and the blue fluorescence of the DAPI stain were examined (Fig. 1) using an Olympus BH2 microscope equipped with a long pass dichroic mirror, type U (DM 400, barrier filter L420).

Variations of this protocol were tested. Following the filtration step, the filter was cut into pieces and incubated over different time periods or with different concentrations of ELF-P. In addition, a comparison was made between the abundance of ELFA spots and the rate of ELF-P hydrolysis measured in a spectrofluorometer calibrated with standard dilutions of ELFA (ref E 6578). This comparison was possible only in cultures, due to the very low sensitivity of ELFA measured spectrofluorometrically. In this attempt, $1.8 \mathrm{ml}$ of Alteromonas infernus culture were incubated with $200 \mu \mathrm{l}$ of a $100 \mathrm{mM}$ Tris$\mathrm{HCl}(\mathrm{pH} 7.5)$ solution and 4 to $40 \mu \mathrm{l}$ of ELF-P (ref E 6588) stock $(5 \mathrm{mM})$ or diluted solutions in Milli-Q water (0.5 mM), giving final ELF-P concentrations of 2 to $100 \mu \mathrm{M}$. The increase in fluorescence (excitation $350 \mathrm{~nm}$, emission $530 \mathrm{~nm}$ ) was followed over time. At the end of the incubation, $500 \mu$ l were sub-sampled, fixed with $1 \%$ final concentration of formaldehyde, and filtered through $0.2 \mu \mathrm{m}$ polycarbonate filters for epifluorescence microscopy and counting of ELFA spots.

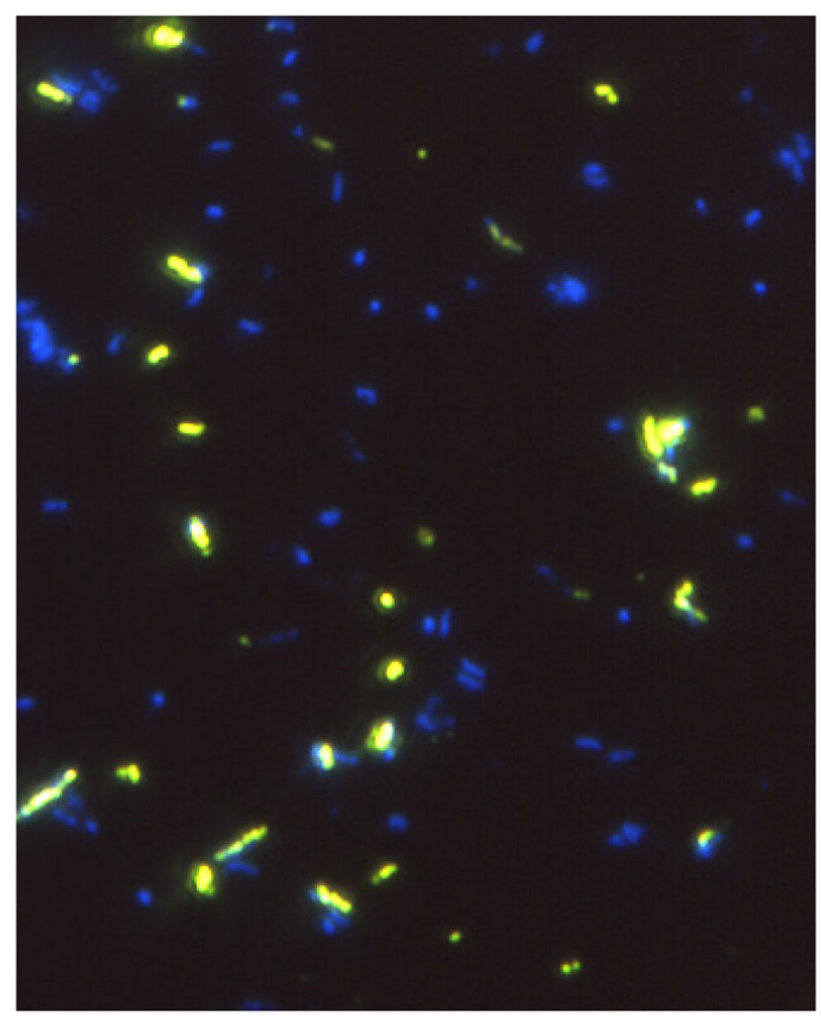

Fig. 1. Alteromonas infernus. ELFA labeled culture (yellowgreen) counterstained with DAPI (blue) as observed with a dichroic mirror type U. Note that the ELFA signal is much more intense than DAPI

\section{RESULTS AND DISCUSSION}

\section{Protocol}

There are several important features in our protocol (see Table 2 for a comparison to previously published protocols). First, in order to work on live and unmodified samples, the ethanol pre-treatment step was omitted, since ethanol may damage cell membranes and/or induce the bleaching of pigments (Nedoma et al. 2003, Dignum et al. 2004). Second, to concentrate the cells, we used filtration because centrifugation requires high speeds and a lengthy processing time, making it less convenient when working on vessels. Third, we used the Endogenous Phosphatase Detection Kit, which is commonly used (Table 2), although only partial information regarding its composition is available (see Dignum et al. 2004, Nedoma et al. 2007). The ELF-P has been used omitting component B of the kit during incubation in the liquid phase (Nedoma et al. 2003), and ELFA precipitation was still possible (Fig. 2c,d). However, this is only feasible in cell-rich water samples with high phosphatase activity (Nedoma et al. 2003, Table 2).

Finally, we used DAPI as a counterstain because both dyes are visible (DAPI-stained bacteria in blue, ELFA spots in yellow-green) and cyanobacteria (orange) and chloroplasts (red) in natural seawater samples are easily discriminated. This also makes the technique compatible with future efforts to combine the method with fluorescent in situ hybridization (FISH) techniques. However, the fluorescence of the ELFA spots is much higher and fades more slowly than DAPI fluorescence (Fig. 1). Consequently, with only visual observation on the microscope, it is impossible to confirm that DAPI-stained cells are associated with an ELFA spot, since their similar size prevents seeing the DAPI stain in the same location as an ELFA spot. However, this discrimination is possible using narrow band filters and image analysis (Nedoma \& Vrba 2006) or flow cytometry (Duhamel et al. 2008).

One of the first assumptions we tested was the presence of a false positive response. We showed that number of cells labeled with ELFA was higher in situations where P-limitation occurred (Table 1 [Expt a], Fig. 3c). Indeed, there was no significant labeling in C-limited cultures of marine bacteria, even at the stationary phase, suggesting that even if the substrate enters senescent cells, intracellular phosphatase cannot significantly react with ELF-P. However, P-sufficient Alteromonas infernus also expressed phosphatase activity (Table 1 [Expt b]), suggesting that for this strain, a fraction of phosphatase activity seemed to be constitutive. These bacteria are thus able to exert significant hydrolysis of phosphomono-ester bonds of organic molecules even in the presence of notable sources of inorganic phosphate. In that 


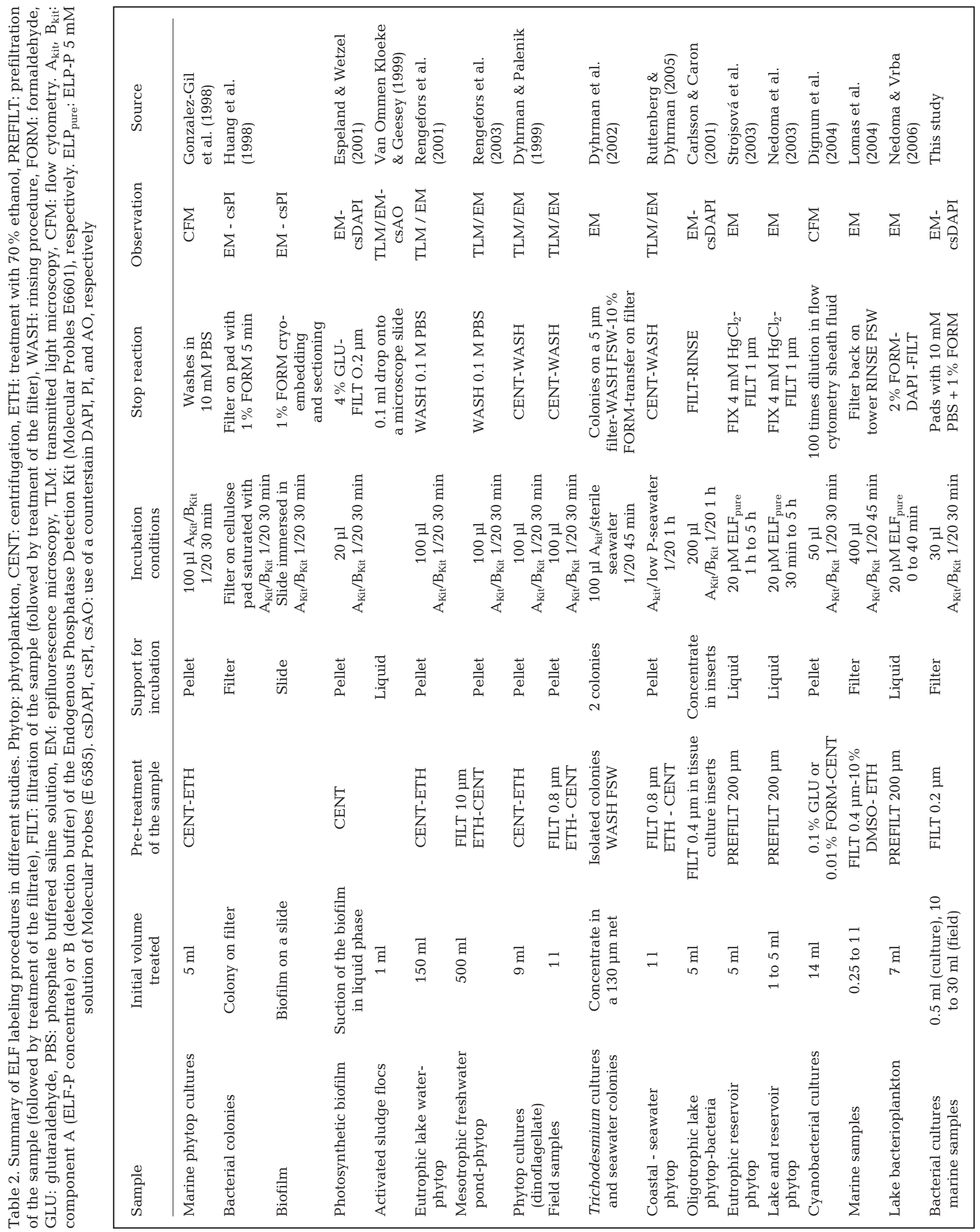



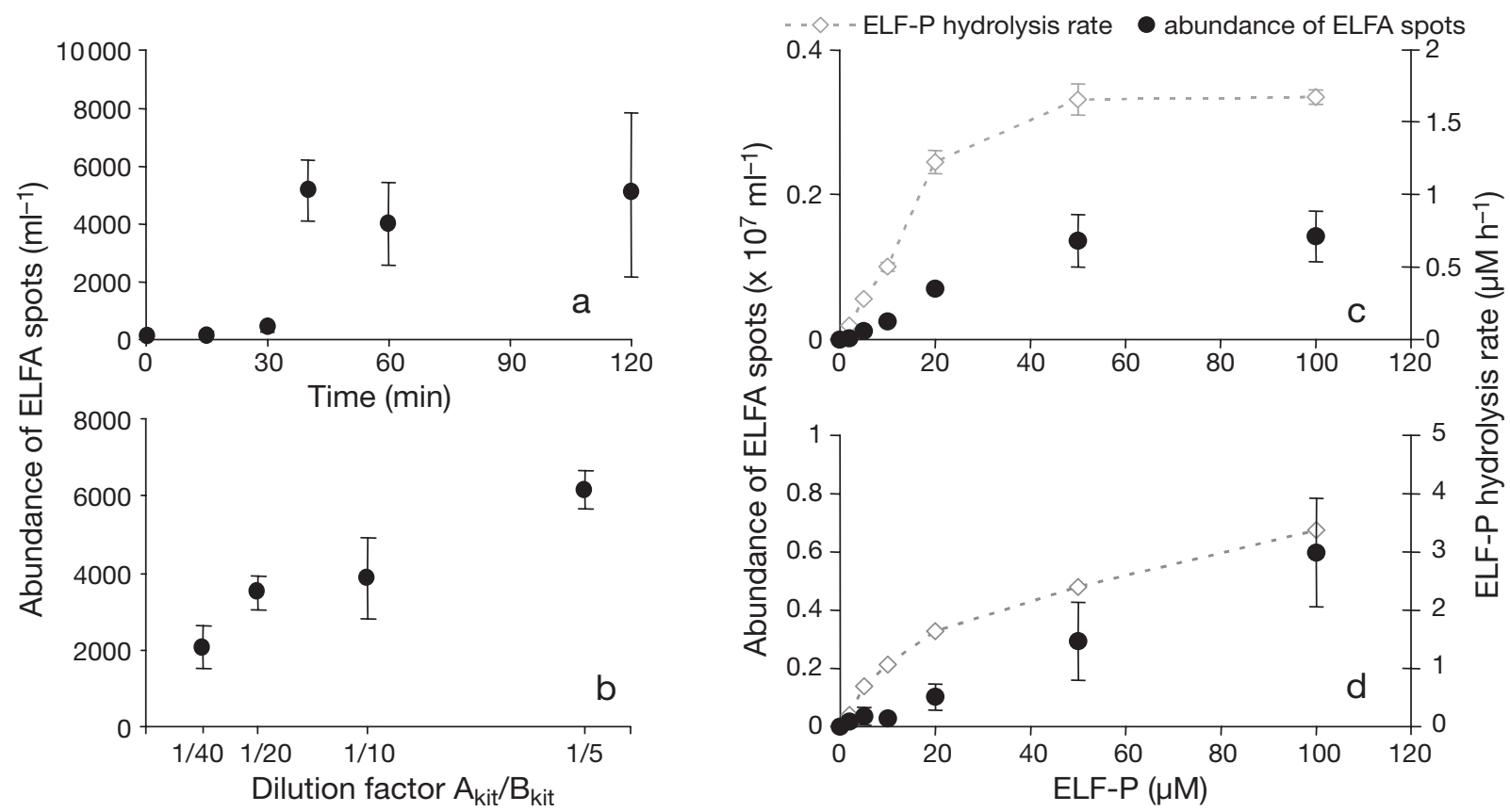

Fig. 2. Typical curves showing the effect of time of incubation (a) and concentration of ELF-P (b,c,d) on the abundance of ELFA spots and ELF-P hydrolysis rates. Data in (a) and (b) used Mediterranean Sea water samples (incubations made on filters). Data in (c) and (d) used pure cultures. ELF-P hydrolysis rate (detected by spectrofluorometry) was measurable only in P-deficient Alteromonas infernus cultures. Error bars are \pm SE within different fields of observation or transects. $A_{\text {kit, }} B_{\text {kit: component } A}$

(ELF-P concentrate) or B (detection buffer) of the Endogenous Phosphatase Detection Kit, respectively
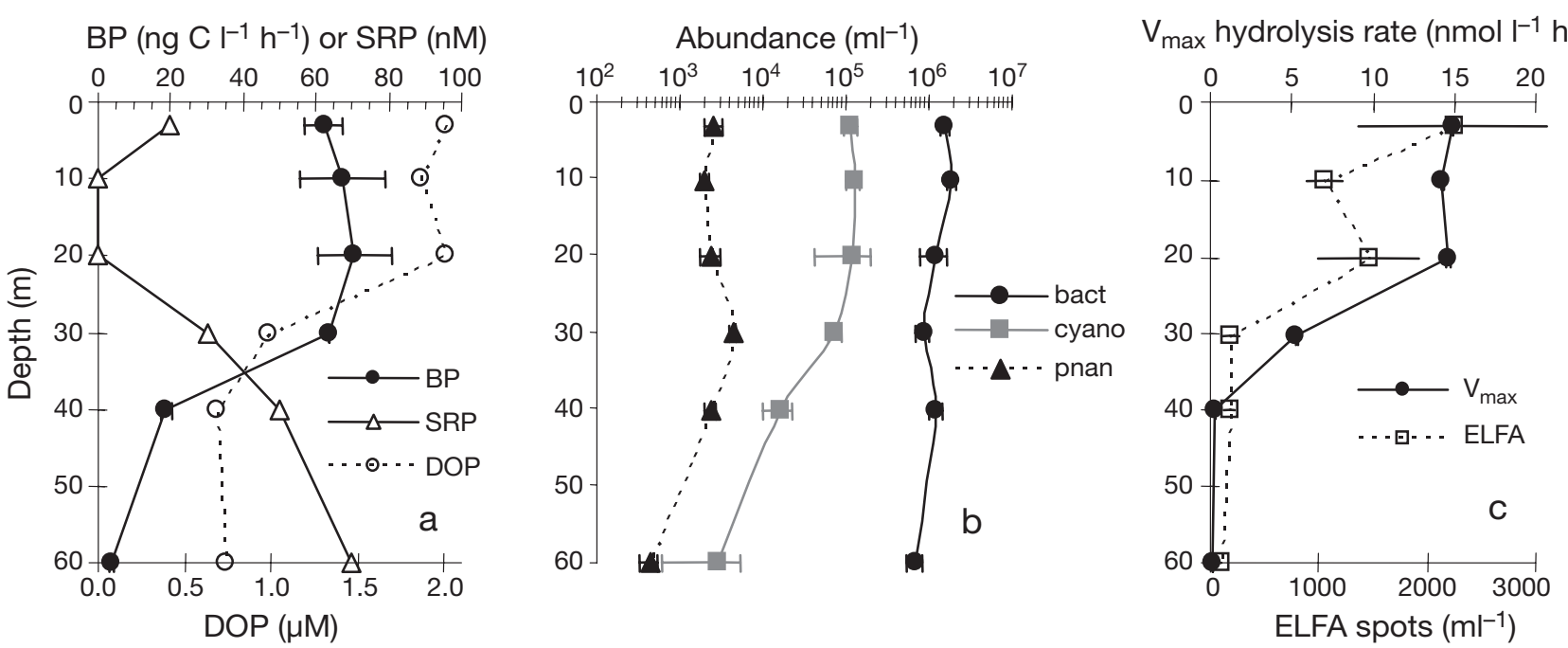

Fig. 3. Vertical profiles of bacterial production (BP), soluble reactive phosphorus (SRP) concentration and dissolved organic phosphorus (DOP) concentration (a); abundances of bacteria (bact), Synechococcus-like cells (cyano), and phototrophic nanoflagellates (pnan) (b); and maximum hydrolysis rate of MUF-P ( $\mathrm{V}_{\max }$ hydrolysis rate) and abundances of ELFA spots (c). All samples were collected at the DYFAMED station, NW Mediterranean Sea, sampled on 30 March 2003

case, this capacity could give access to the $\mathrm{C}$ or $\mathrm{N}$ compounds of the molecule hydrolyzed in environments deficient in labile sources of organic matter, like the deep sea (Hoppe \& Ullrich 1999).

The Time 0 sample (acting as an abiotic control, because it was fixed with formalin) only exhibited a low fluorescence signal, thus confirming the absence of signifi- cant abiotic labeling with ELF-P. Development of ELFA spot abundances over time in the incubations confirmed the presence of a lag phase that was apparent in cultures as well as in natural samples (Fig. 2a). This lag time was also reported for freshwater phytoplankton (Nedoma et al. 2003, Dignum et al. 2004) and can vary with activity, temperature, and cell size (J. Nedoma unpubl. results). A 
maximum concentration of label was obtained generally within $1 \mathrm{~h}$ in natural samples. Both the number of ELFA spots and ELF-P hydrolysis rates (measured by fluorometry) increased with the concentration of ELF-P added. The shape of these curves was not reproducible from one sample to another (Fig. 2c,d), suggesting that the range of concentrations that we tested was not always sufficient to reach maximum hydrolysis rates, or that multiphasic kinetics were present (presence of different enzymes: Hoppe 2003, Nedoma \& Vrba 2006). These tests confirmed that the typical $1 / 20$ dilution of the solutions in the kit we used (i.e. $250 \mu \mathrm{M}$ ) in the $1 \mathrm{~h}$ incubation is generally sufficient to optimize cell labeling.

\section{Bacterial cultures}

All tests carried out using cultures are summarized in Table 1. Maximum bacterial abundances were higher under excess-P than under low-P conditions. However, bulk activity and cell-specific activities varied depending on the strain. For Alteromonas infernus, differences between low-P and excess-P conditions were less pronounced than for Pseudomonas denitrificans. Occasionally, the average ratio of ELFA spots to DAPI counts was $>1$. Because ELFA spots and DAPI counts were made on 2 separate slides, it is difficult to conclude that percentages higher than $100 \%$ were really due to the formation of ELFA spots outside bacterial cells or to heterogeneity in the distribution of bacteria on the slide when abundances reached $10^{7}$ cells $\mathrm{ml}^{-1}$.

\section{Seawater samples}

Sampling was carried out during the spring phytoplankton bloom (Bourguet et al. in press) when heterotrophic bacteria $\left(1.5 \times 10^{6} \mathrm{ml}^{-1}\right)$ and Synechococcuslike cells $\left(1 \times 10^{5} \mathrm{ml}^{-1}\right)$ were abundant (Fig. 3b). SRP was below $20 \mathrm{nM}$ or undetectable in surface layers down to $20 \mathrm{~m}$ depth (Fig. 3a). MUF-based AP activity was constant in the first $20 \mathrm{~m}$ of the profile and decreased significantly at $30 \mathrm{~m}$ depth (Fig. 3c). The Michaelis-Menten constant $\left(K_{\mathrm{m}}\right)$ was stable along the profile, with values ranging from 83 to $116 \mathrm{nM}$ (results not presented). At most, we counted $2 \times 10^{3}$ ELFA spots $\mathrm{ml}^{-1}$ at any particular location along the profile. Being aware of the difficulty of counting rare events on filters, the vast majority of these spots were identified as unassociated spots (34 to $75 \%$ over the depth range), in contrast to spots associated with detritus (yellow DAPI particles without chlorophyll fluorescence, 21 to $55 \%$ ), and only a few spots were associated with identified orange fluorescent cell (cyanobacteria, 0 to $8 \%$ ) or red fluorescent cells (phototrophic nanoflagellates, 0 to $8 \%$ ). The highest ratio of total ELFA spots to bacterial abundance reached was $0.01 \%$.

A log-log plot of the distribution of ELFA spot abundance versus MUF-P based AP activity using the entire data set is shown in Fig. 4. Below a threshold of 5 to $10 \mathrm{nmol}$ MUF-P hydrolyzed $\mathrm{l}^{-1} \mathrm{~h}^{-1}$, a range that is frequently found in situ, there was no significant relationship due to the high variability. MUF-P activity was linearly related to ELFA spots over a range of 5 to $200 \mathrm{nmol} \mathrm{l}^{-1} \mathrm{~h}^{-1}$. At MUF-P hydrolysis rates higher than $200 \mathrm{nmol} \mathrm{l}^{-1} \mathrm{~h}^{-1}$, ELFA spot abundance leveled off.

\section{CONCLUSIONS}

Culture populations and field communities of heterotrophic bacteria exhibited different phosphatase activities as seen from the specific activities found with MUF-P substrate and the varying percentages of ELF labeling. A minimum threshold of extracellular phosphatase activity (measured by spectrofluorometry) of $10 \mathrm{fmol} \mathrm{cell}^{-1} \mathrm{~h}^{-1}$ for phytoplankton (Nedoma et al. 2003) and $0.17 \mathrm{fmol} \mathrm{cell}^{-1} \mathrm{~h}^{-1}$ for bacteria in acidified mountain lakes (Nedoma \& Vrba 2006) is necessary to observe significant ELFA spot formation and to allow quantitative per cell estimates. Such levels were reached only in our cultures. In contrast, we were unable to detect ELFA labeling of bacteria from marine samples with the protocol developed in this study, even though SRP concentrations were undetectable in surface waters and MUF-P hydrolysis rates were relatively high. Heterotrophic bacteria were P-stressed, as shown by the stimulation of bacterial production after

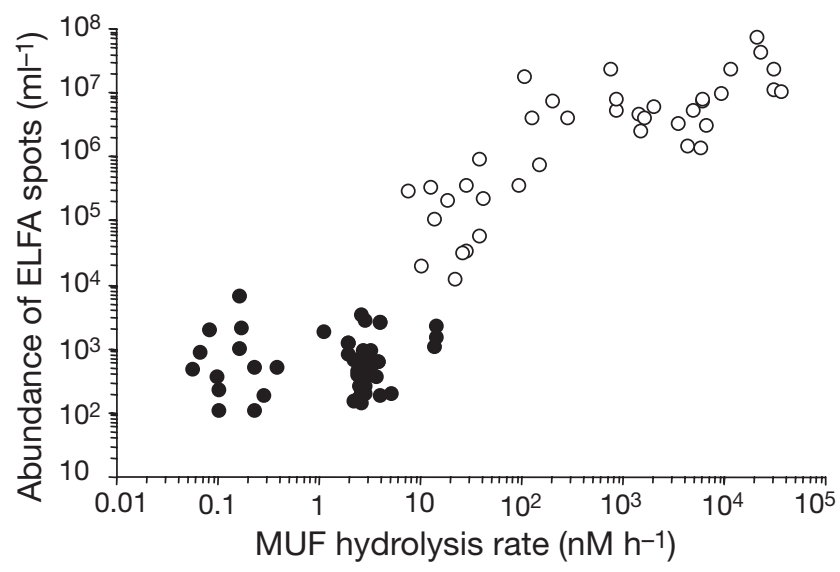

Fig. 4. Log-log plot of abundance of ELFA spots versus MUF-P alkaline phosphatase activities using the whole data set; culture data presented in Table 1, profile of March 2003 (Fig. 3), and other measurements made using the same protocol within surface waters at the DYFAMED station in October 2004 (results not presented in text). Solid symbols represent in situ data, open symbols are pure cultures 
$\mathrm{P}$ amendments (results not presented). It is likely that either the concentration of ELF-P we added was different from the affinity of bacteria for this molecule, or that assay conditions were not optimal, e.g. only the most active bacteria were labeled. This problem has also been encountered with natural Synechococcus cells in the North Atlantic Gyre (Lomas et al. 2004). Detection of extracellular activity among small coccoids in an acidified lake was scarce, and when detectable, activity was lower than that of filaments and curved rods that systematically revealed higher activities (Nedoma \& Vrba 2006). Future research should concentrate on more sensitive detection techniques such as flow cytometry, which could allow the detection of a greater number of events and the simultaneous quantification of ELF intensity per cell with a faster procedure than quantification by image analysis. This work is currently in progress.

Acknowledgements. We thank P. Catala for providing us with some marine strains from the AIRWIN collection; P. Raimbault, N. Garcia, and T. Moutin for providing us PP, SRP, and DOP data; and M. Goutx as one of the PIs of the PECHE project. Valuable comments and English improvement from 3 anonymous reviewers and J. Edmonds are appreciated. This study was supported by INSU-CNRS through the French program PROOF-PECHE, and by the PAI Barrande project 200506-009-01. This work is dedicated to V. Andersen, PI of the PECHE project, who passed away in March 2007.

\section{LITERATURE CITED}

Bourguet N, Ghiglione JF, Pujo-Pay M, Mevel G and others (in press) Relationship between organic matter composition and bacterial dynamics during mesotrophic and oligotrophic conditions in the NW Mediterranean Sea. Deep-Sea Res Part II

Carlsson P, Caron DA (2001) Seasonal variation of phosphorus limitation of bacterial growth in a small lake. Limnol Oceanogr 46:108-120

Dignum M, Hoogveld H, Matthijs HC, Laanbroek HJ, Pel R (2004) Detecting the phosphate status of phytoplankton by enzyme labelled fluorescence and cytometry. FEMS Microbiol Ecol 48:29-38

Duhamel S, Grégori G, Van Wambeke F, Mauriac R, Nedoma J (2008) A method for analysing phosphatase activity in aquatic bacteria at the single cell level using flow cytometry. J Microbiol Methods (in press)

> Dyhrman ST, Palenik B (1999) Phosphatase stress in cultures and field populations of the dinoflagellate Prorocentrum minimum detected by a single cell alkaline phosphatase assay. Appl Environ Microbiol 65:3205-3212

Dyhrman ST, Webb EA, Anderson DM, Moffet JW, Waterbury JB (2002) Cell-specific detection of phosphorus stress in Trichodesmium from the Western North Atlantic. Limnol Oceanogr 47:1832-1836

Espeland EM, Wetzel RG (2001) Effects of photosynthesis on bacterial phosphatase production in biofilms. Microb Ecol 42:328-337
Gonzalez-Gil S, Keafer BA, Jovine RV, Aguilera A, Lu S, Anderson DM (1998) Detection and quantification of alkaline phosphatase in single cells of phosphorus-starved marine phytoplankton. Mar Ecol Prog Ser 164:21-35

> Hoppe HG (2003) Phosphatase activity in the sea. Hydrobiologia 493:187-200

> Hoppe HG, Ullrich S (1999) Profiles of ectoenzymes in the Indian Ocean: phenomena of phoshatase activity in the mesopelagic zone. Aquat Microb Ecol 19:139-148

Huang CT, Xu KD, McFeters G, Stewart P (1998) Spatial pattern of alkaline phosphatase expression with bacterial colonies and biofilms in response to phosphate starvation. Appl Environ Microbiol 64:1526-1531

Lomas MW, Swain A, Shelton R, Amermann JW (2004) Taxonomic variability of phosphorus stress in Sargasso Sea phytoplankton. Limnol Oceanogr 49:2303-2310

Lyman J, Fleming RH (1940) Composition of seawater. J Mar Res 3:134-146

Marty JC, Chiavérini J, Pizay MD, Avril B (2002) Seasonal and interannual dynamics of nutrients and phytoplankton pigments in the western Mediterranean Sea at the DYFAMED time series station, 1991-1999. Deep Sea-Res Part II 49:1965-1985

> Nedoma J, Vrba J (2006) Specific activity of cell-surface acid phosphatase in different bacterioplankton morphotypes in an acidified mountain lake. Environ Microbiol 8: 1271-1279

Nedoma J, Štrojsová A, Vrba J, Komárková J, Šimek K (2003) Extracellular phosphatase activity of natural plankton studied with ELF 97 phosphate: fluorescence quantification and labelling kinetics. Environ Microbiol 5:462-472

Nedoma J, Garcia JC, Comerma M, Šimek K, Armengol J (2006). Extracellular, phosphatases in a mediterranean reservoir: seasonal, spatial and kinetic heterogeneity. Freshw Biol 51:1264-1276

> Nedoma J, Van Wambeke F, Štrojsová A, Štrojsová M, Duhamel S (2007) Affinity of extracellular phosphatases for ELF97 phosphate in aquatic environments. Mar Freshw Res 58:454-460

Raimbault P, Pouvesle W, Diaz F, Garcia N, Sempéré R (1999) Wet-oxidation and automated colorimetry for simultaneous determination of organic carbon, nitrogen and phosphorus dissolved in seawater. Mar Chem 66:161-169

Rengefors K, Petterson K, Blenckner T, Anderson DM (2001) Species-specific alkaline phosphatase activity in freshwater spring phytoplankton: application of a novel method. J Plankton Res 23:435-443

Rengefors K, Ruttenberg KC, Haupert CL, Taylor C, Howes BL, Anderson DM (2003) Experimental investigation of taxon-specific responses of alkaline phosphatase activity in natural freshwater phytoplankton. Limnol Oceanogr 48:1167-1175

Ruttenberg KC, Dyhrman ST (2005) Temporal and spatial variability of dissolved organic and inorganic phosphorus, and metrics of phosphorus bioavailability in an upwellingdominated coastal system. J Geophys Res 110:C10S13, doi:10.1029/2004JC002837

Štrojsová A, Vrba J, Nedoma J, Komárková J, Znachor P (2003) Seasonal study of extracellular phosphatase expression in the phytoplankton of a eutrophic reservoir. Eur J Phycol 38:295-306

Van Ommen Kloeke F, Geesey G (1999) Localization and identification of populations of phosphatase active bacterial cells associated with activated sludge flocs. PSZN I: Mar Ecol 38:201-214

Submitted: November 6, 2007; Accepted: July 29, 2008

Proofs received from author(s): September 1, 2008 